\title{
OPEN Comparative genome analysis of Bacillus thuringiensis strain HD521 and HS18-1
}

\author{
Hongwei Sun ${ }^{1,2,4}$, Xing Xiang ${ }^{1,4}$, Qiao Li $^{1}$, Hui Lin ${ }^{1}$, Xiaolin Wang ${ }^{1}$, Jie Sun ${ }^{3}$, Long Luo ${ }^{2 \bowtie} \&$ \\ Aiping Zheng ${ }^{1 \bowtie}$
}

Bacillus thuringiensis ( $B t$ ) is an important biological insecticide used to management of different agricultural pests by producing toxic parasporal crystals proteins. Strain HD521 has an antagonistic effect against Rhizoctonia solani AG1IA, the causal agent of rice sheath blight. This strain with three cry7 genes can the formation of bipyramidal parasporal crystals (BPCs). BPCs are used for insecticidal activities against Henosepilachna vigintioctomaculata larva (Coleoptera). Strain HS18-1 contains different types of BPCs encoding genes and has effective toxicity for Lepidoptera and Diptera insects. Here we report the whole genome sequencing and assembly of HD521 and HS18-1 strains and analyzed the genome constitution covering virulence factors, types of plasmid, insertion sequences, and prophage sequences. The results showed that the genome of strain HD521 contains a circular chromosome and six circular plasmids, encoding eight types of virulence protein factors [Immune Inhibitor A, Hemolytic Enterotoxin, S-layer protein, Phospholipase C, Zwittermicin A-resistance protein, Metalloprotease, Chitinase, and $\mathrm{N}$-acyl homoserine lactonase (AiiA)], four families of insertion sequence, and comprises six pro-phage sequences. The genome of strain HS18-1 contains one circular chromosome and nine circular plasmids, encoding five types of virulence protein factors [Hemolytic Enterotoxin, S-layer protein, Phospholipase $\mathrm{C}$, Chitinase, and $\mathrm{N}$-acyl homoserine lactonase (AiiA)] and four families of insertion sequence, and comprises of three pro-phage sequences. The obtained results will contribute to deeply understand the $B$. thuringiensis strain HD521 and HS18-1 at the genomic level.

Bacillus thuringiensis $(B t)$ is a ubiquitous, Gram-positive, spore-forming bacterium ${ }^{1}$. The strains of this species are used as a successful biopesticide in many countries. It can produce insecticidal parasporal crystal proteins ${ }^{2,3}$. These crystal proteins are known as $\delta$-endotoxins, which are specifically toxic to different pests, including species of the Lepidoptera, Coleoptera, Diptera, Hymenoptera, and Homoptera, as well as some nematodes ${ }^{1,4}$. Due to the toxins specific insecticidal activities, they are non-toxic to humans, therefore which were widely used to control insects in agriculture ${ }^{5,6}$. A previous study showed that Bt could also produce some antibiotics, such as Zwittermycin A, to enhance its insecticidal toxins and inhibit pathogenic bacteria ${ }^{7-9}$. The complete antibiotic biosynthesis gene cluster was first identified in the strain $B$. cereus $\mathrm{UW} 85^{10}$. B. thuringiensis can also produce some virulence factors when insects are infected, such as enhances and collagenases ${ }^{11,12}$. Plasmid often encodes many virulence genes play significant roles in pathogenesis in these bacteria. Virulence genes are located on the plasmids usually give rise to different phenotypes and pathologies ${ }^{13}$. The availability of the genome sequences of $B$. cereus group members such as B. anthracis A2012 $2^{14}, B$. cereus ATCC $14579^{15}$, and B. anthracis Ames ${ }^{16}$, play an important role in supporting the identification of unique metabolism, comparative physiology, sporulation, and virulence.

To date, many countries were interesting to dig the resources of $B t$ strains, and thousands of $B t$ strains were isolated. But the genomic informations of most strains are not complete, especially those highly toxic strains used for pest control since the last century. Although $42 \mathrm{~B}$. thuringiensis strains have been sequenced, gapless chromosomes and plasmids have only been obtained from 15 strains' (http://www.ncbi.nlm.nih.gov/genome/ genomes/486) ${ }^{17}$ In this study, based on the previous research, in order to have a deeper understanding of the structure, function, regulation mechanism and evolutionary laws of strains HD521 and HS18-1, and to provide

${ }^{1}$ College of Agronomy, Sichuan Agricultural University, Wenjiang 611130, China. ${ }^{2}$ Wenshan Academy of Agricultural Sciences, Wenshan 663000, China. ${ }^{3}$ College of Agronomy, Shihezi University, Shihezi 832003, China. ${ }^{4}$ These authors contributed equally: Hongwei Sun and Xing Xiang. ${ }^{凶}$ email: dzhx77@163.com; apzh0602@ gmail.com 
a scientific basis for inhibiting the pathogenicity of pathogenic bacteria and preventing insect pests. Here, we introduced the genome information of the two strains in detail.

\section{Materials and methods}

Materials. The strain HD521 belongs to the Indiana subspecies (Indiana) and was obtained from Bacillus Genetic Stock Center (BGSC). Strain HS18-1 was isolated from the Sichuan Basin of China and was stored in our laboratory. Genomic extract reagent (QIAGEN Genomic-tip 500/G) was purchased from QIAGENgs, The cloning vector Trans1-T1 and E. coli DH5a were purchased from the full-scale gold company.

\section{Methods}

Sequencing and assembly of strain HD521. The mixture of total DNA and plasmid of strain HD521 is randomly interrupted by using Ultrasonic Disruptor (method: ultrasound for $30 \mathrm{~s}$, with an interval of $30 \mathrm{~s}, 10$ cycles is 1 time; take out the sample, vortex and mix, then put it back into ultrasonic breaker to continue ultrasonic interruption. The whole process need three times). Then construct a sequencing library for the interrupted total DNA according to Illumina's paired-end library construction kit was done. Finally, Sequencing using Illumina HiSeq 2000 platform at Beijing Genomics Institute (BGI; Shenzhen, China) (BGI) was completed. The sequencing structure was de nove assembled by using software Velvet 1.2.10 ${ }^{18}$. Simultaneously, paired-end reads sequencing are anchored to the assembled fragments by using software Burrows-Wheeler Aligner's SmithWaterman Alignment to verify the accuracy of sequence assembly ${ }^{19}$.

Sequencing and assembly of strain HS18-1. The genome sequencing strategy of strain HS18-1 is the second-generation sequencing technology combined with the third-generation sequencing technology-single molecular, real time, circular consensus sequencing (SMRT), Similar to strain HD521, when sequencing, the Hiseq 2000 platform was used, a pair-end library was constructed, and insert sequence length was two kbp and $200 \mathrm{bp}$. A library with an insert length of $10 \mathrm{kbp}$ was constructed in single-molecule real-time sequencing, according to the SMRT sequencing library construction instructions. The data obtained by HiSeq 2000 sequencing platform was assembled using the software Velvet, 1.2.10. The obtained sequence is used to assemble and correct the accuracy of some sequences in the third-generation sequencing ${ }^{20}$, the assembly of the third-generation sequencing data using SMRT analysis assembly software Velvet, 2.3.021.

Assembly and result verification of complete genome-wide maps. The results of cloning and sequencing are compared with the border sequences on Scaffolds, more than $99 \%$ completely matches sequence in the border sequences been known as a gap closing sequence, so this corresponding fragment can connect two different scaffolds, Some sequencing results cannot completely match with the boundary sequence of two Scaffolds, but it can be matched with the boundary sequence of one of the Scaffolds. In this case, we consider that the sequence can effectively extend the matching Scaffold. Then to design primers, amplify, clone, and compare from newly extended sequences until the two Scaffolds are spliced together.

In the process of sequence splicing, if there is some genomic repetitive sequences and regions with low base reliability, their corresponding primers are designed, to amplify, clone, and sequencing verification. In this way, the error rate of the genome is lower than one $\mathrm{bp} / 10 \mathrm{~kb}$, thereby improving the accuracy of genome splicing and assembly.

Gene annotation of genomes and plasmids, and prediction of open reading frames. The Open Reading Frame (ORF) of whole genome of HD521 and HS18-1 was predicted by using GeneMarks software with default parameters ${ }^{22}$. The protein coding sequences of whole genome were predicted by applying Glimmer $3.02^{23}$, rRNA, tRNA and sRNA were predicted by rRNAmmer, tRNAscan and Rfam, respectively ${ }^{24-26}$. The genes of signal peptides and transmembrane helices were predicted by SinnalP 3.0 and TMHMM 2.0 27,28 .

Circular genome graph of strain HD521 and HS18-1. The circle graph of genome and plasmid of strain HD521 and HS18-1 was drew by using Circos software (Biomarker Biotechnology Co., Ltd; Beijing, China), The circle graph indicates the scale ruler, the forward strand and reverse strand of DNA, and the GC content of the genome; GC skew; classification of different genes.

Analysis of genome insertion sequence of strain HD521 and HS18-1. According to the genome data of HD521 and HS18-1, Insertion sequence (IS) of genomic and plasmid sequences were aligned by using the ISsaga program in IS FINDER, and the distribution of IS sequences was analyzed (http://issaga.biotoul.fr/ issaga_index.php). After confirmation of the transposase gene, the selected sequence at the upper and lower $300 \mathrm{bp}$ nucleotide sequence of the transposase gene was aligned for the analysis of IS sequence structure. IR region of IS sequence and DR region at the both ends of IR region was found. For some IS sequences, if IR region cannot be confirmed, the search range of upstream and downstream sequences at the transposase gene was enlarged to find and confirm the DR region.

Sequence analysis of HD521 and HS18-1 genome prophage. The distribution of whole genome sequence and lysogenic phage sequences in plasmids of HD521 and HS18-1 were analyzed by using PHAST (http://phast.wishartlab.com/index.html) ${ }^{29,30}$. 

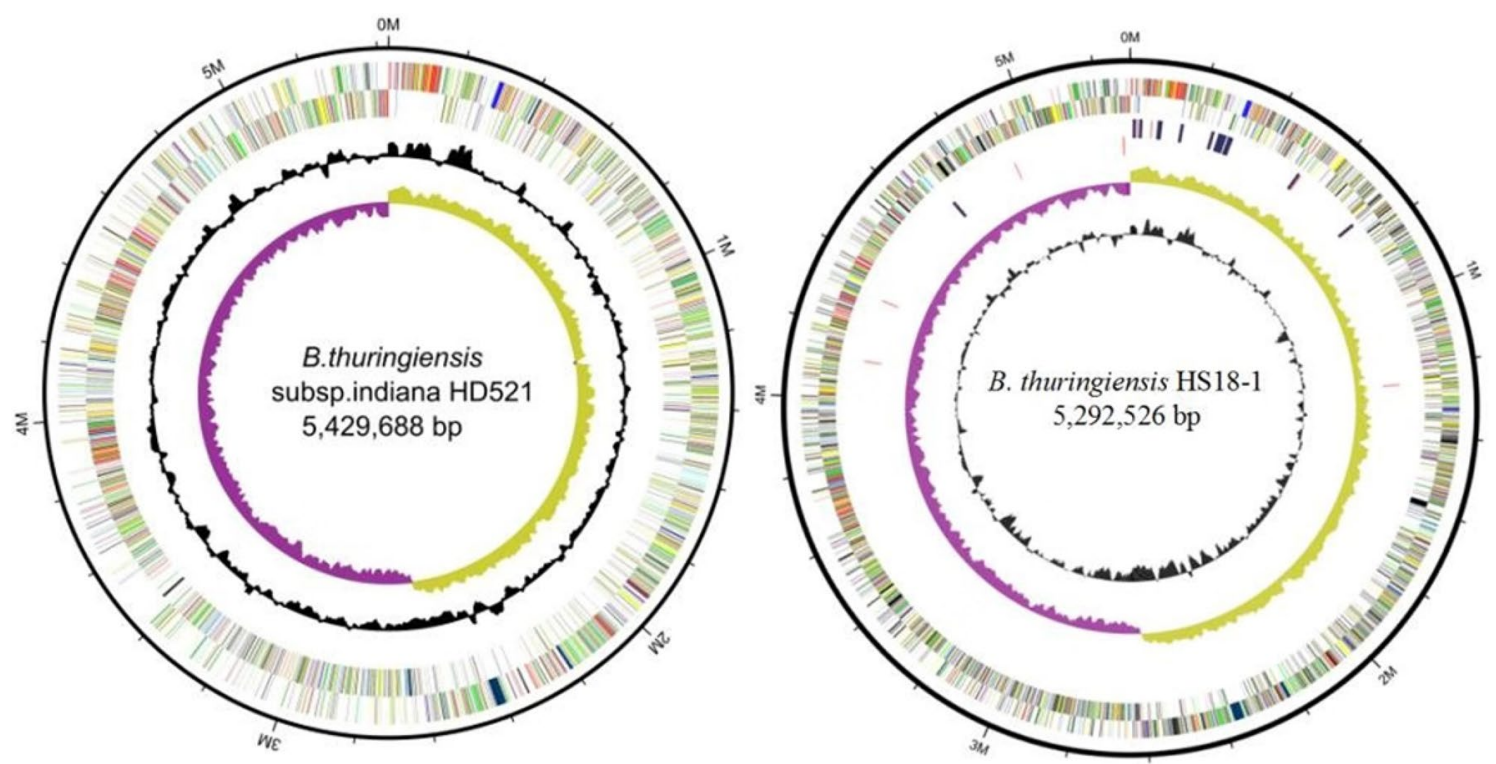

Figure 1. Circular pictorial representation of chromosome of both $B t$ strains; (A) Bt strain HD521 and (B) Bt strain HS18-1. From outside to center: the first circle, the forward strand of DNA; the second circle, the reverse strand of DNA; the third circle GC content (black), the fifth circle GC skew.

Virulence factors analysis of HD521 and HS18-1 genome. Virulence factor gene and protein sequence information in Bacillus cereus group (B. cereus, B. anthrax and B. thuringiensis) were collected, and a virulence factor gene set (protein sequence set) is constructed, and then Homology comparison the annotation results of HD521 and HS18-1 genomes and plasmids with the gene set, then get a gene set of predicting virulence genes and their sequences were analyzed by using BLAST software, Finally, the virulence factor sequence information of HD521 and HS18-1 were obtained.

\section{Results and analysis}

Features of strain HD521 and HS18-1. Bt strain HD521 was first isolated from soil sample of the United States $^{31}$. It was obtained from Bacillus Genetic Stock Center (BGSC). Strain HD521, like the majority of the $B t$ strains, cells are Gram-positive and rod-shaped ${ }^{1}$. It exhibits maroon colonies and produces bipyramidal parasporal crystals (BPCs) during the stationary phase of its growth cycle. But, the difference is that its colonies can produce brown-red pigments that turn the entire colony into brownish. SDS-PAGE analysis of spores and crystals mixtures showed the strain HD521 expression of a major protein band of $130 \mathrm{kDa}$, which is consistent with the following analysis of its parasporal crystal gene ${ }^{32}$. However, strain HS18-1 was isolated from the Sichuan basin of China, and it has typical toxicity against Lepidoptera and Diptera ${ }^{33}$. It can produce spherical parasporal crystals during the stationary phase of its growth cycle. SDS-PAGE analysis of spores and crystals mixtures showed HS18-1 expression of two major protein band of $130 \mathrm{kDa}$ and $75 \mathrm{kDa}^{34}$. By identifying insecticidal gene, it indicated that strain HS18-1 contains very rich cry-type insecticidal crystal protein genes, including cry4Cb1, cry30Ga1, cry30Ea1, cry56Aa3, cry50Aa, cry69Ab1, cry70Aa, cry71Aa, and cry72 Aa ${ }^{33,34}$.

Genomic composition of strain HD521 and HS18-1. The genome of HD521 consisted of seven replicons: a circular chromosome (Fig. 1) and 6 circular plasmids. The GC content of the circular chromosome with a length of $5,429,688 \mathrm{bp}$ is $35.28 \%$. It included a predicted 5538 genes and 138 are RNA genes. Total of these 5400 genes with a collective length of 4,544,493 bp, are protein-encoding genes. 6 of the plasmids are named pBTHD521-1, pBTHD521-2, pBTHD521-3, pBTHD521-4, pBTHD521-5, and pBTHD521-6. The GC content of the six plasmids ranged from 29.45 to $35.91 \%$ and contained a total of 772 predicted genes. However, the genome of HS18-1 consists of 10 replicons with one circular chromosome (Fig. 1) and 9 circular plasmids. The gapless circular chromosome with a length of 5,292,526 bp (35.43\% GC content) contains 5382 genes, 148 of total are RNA genes, and total of these, 5234 are protein-encoding genes. 9 of the plasmids are named pHS18-1, pHS18-2, pHS18-3, pHS18-4, pHS18-5, pHS18-6, pHS18-7, pHS18-8, and pHS18-9. The GC content of 9 plasmids is ranged from 28.49 to $37.07 \%$ and consist total 892 predicted genes (Table 1 ).

Although both the HD521 and HS18-1 genomes carry plasmids, but the HS18-1 have more plasmids than the HD521, and reached 9. The largest plasmid pHS18-1 is 509,170 bp, the smallest plasmid pHS18-9 is $7386 \mathrm{bp}$.

Virulence factors. The insecticidal active ingredients of strains HD521 and HS18-1 are mainly encoded insecticidal crystal proteins on the plasmid. In addition, the chromosomes also encode a large number of insecticidal active ingredients (Table 2), and their insecticidal mechanisms are also different. Moreover, there is synergistic effect between the insecticidal active ingredients. 


\begin{tabular}{|c|c|c|c|c|c|c|c|c|c|c|c|}
\hline \multirow[b]{2}{*}{ Feathers } & \multirow[b]{2}{*}{ Length(bp) } & \multicolumn{4}{|l|}{ HD521 } & \multirow[b]{2}{*}{ Feathers } & \multirow[b]{2}{*}{ Length (bp) } & \multicolumn{4}{|l|}{ HS18-1 } \\
\hline & & $\begin{array}{l}\text { G+C content } \\
(\%)\end{array}$ & Coding genes & rRNA & tRNA & & & $\begin{array}{l}\text { G+C content } \\
(\%)\end{array}$ & Coding genes & rRNA & tRNA \\
\hline Chromosome & $5,429,688$ & 35.28 & 5538 & 31 & 107 & Chromosome & $5,292,526$ & 35.43 & 5382 & 42 & 106 \\
\hline $\begin{array}{l}\text { Plasmid } \\
\text { pBTHD521-1 }\end{array}$ & 7042 & 11 & 29.45 & 0 & 0 & Plasmid pHS18-1 & 509,170 & 32.71 & 417 & 0 & 0 \\
\hline $\begin{array}{l}\text { Plasmid } \\
\text { pBTHD521-2 }\end{array}$ & 49,838 & 70 & 35.91 & 0 & 0 & Plasmid pHS18-2 & 337,579 & 33.25 & 357 & 0 & 0 \\
\hline $\begin{array}{l}\text { Plasmid } \\
\text { pBTHD521-3 }\end{array}$ & 71,771 & 89 & 34.37 & 0 & 0 & Plasmid pHS18-3 & 92,085 & 31.06 & 91 & 0 & 0 \\
\hline $\begin{array}{l}\text { Plasmid } \\
\text { pBTHD521-4 }\end{array}$ & 71,646 & 103 & 29.79 & 0 & 0 & Plasmid pHS18-4 & 94,695 & 33.54 & 79 & 0 & 0 \\
\hline $\begin{array}{l}\text { Plasmid } \\
\text { pBTHD521-5 }\end{array}$ & 253,580 & 243 & 33.08 & 0 & 0 & Plasmid pHS18-5 & 42,726 & 42,726 & 59 & 0 & 0 \\
\hline \multirow[t]{4}{*}{$\begin{array}{l}\text { Plasmid } \\
\text { pBTHD521-6 }\end{array}$} & 314,883 & 256 & 31.99 & 0 & 0 & Plasmid pHS18-6 & 14,336 & 36.17 & 9 & 0 & 0 \\
\hline & & & & & & Plasmid pHS18-7 & 4669 & 37.07 & 7 & 0 & 0 \\
\hline & & & & & & Plasmid pHS18-8 & 8287 & 28.49 & 6 & 0 & 0 \\
\hline & & & & & & Plasmid pHS18-9 & 7386 & 32.29 & 4 & 0 & 0 \\
\hline
\end{tabular}

Table 1. Genomic composition of Bacillus thuringiensis strain HD521 and HS18-1.

Strain HD521 comprises a plethora of virulence factors such as Immune Inhibitor A, Hemolytic Enterotoxin, S-laryer protein, Phospholipase C, Zwittermicin A-resistance protein, Metalloprotease, Chitinase, and $N$-acyl homoserine lactonase (AiiA). Immune Inhibitor A is a metallo-enzyme, it have three copies on the chromosome of strain HD521, which able to enhance toxicity to insects by inhibiting insect immune factors and hydrolyzing some antibacterial proteins in insects. The chromosome of strain HD521 encodes 9 enterotoxin genes, it is a virulence factor contained in Bacillus cereus which causes vomiting and diarrhea in humans. However, we conclude that strain HD521 may have hemolytic properties due to 3 subunit genes, Gamma-hemolysin component B, Tripartite hemolysin BL component L1, and Hemolysin BL lytic component L2, encoded in chromosome of strain HD521.

The S-layer protein forms an ordered crystal array structure on the surface of pathogenic bacteria that maintains cell morphology and cell integrity, so it belongs to a class of surface proteins and is widely distributed in Bacillus species. The S-layer protein of Bt have synergistic effects on insecticidal crystal proteins. Phospholipase $\mathrm{C}$ can hydrolyze phosphatidyl alcohol and phosphatidyl choline, which can also cause certain damage to the intestinal tract of insects and promote the activity of insecticidal crystal proteins in a certain extent ${ }^{35}$. Zwittermicin is a new broad-spectrum antibiotic that can inhibit the growth of a variety of microorganisms, especially oomycetes and their related bacteria. But the chromosome of Bt HD521 contains two resistant genes for Zwittermicin, Zwittermicin A-resistance protein and Zwittermicin A resistance protein zmaR. Therefore, we conclude that Bt HD521 has certain resistance to Zwittermicin. Chitin is also known as shell polysaccharide, which is widely found in the shells of insects, the shells of crustaceans and the cell walls of fungi, and acts as a support skeleton to protect itself. Meanwhile, Chitinase is an enzyme that can hydrolyzes chitin, its main role is to has a synergistic effect on pesticides. Because the chitin is one of the main component of the insect midgut peritrophic membrane, the peritrophic membrane is the barrier of insects against bacteria and viruses, when the peritrophic membrane is destroyed by chitinase, the activity of insecticidal protein ultimately increases ${ }^{36-38}$. The strain HD521 chromosome encodes two types of chitinases, chitinase A and chitinase D, which can hydrolyze the outer wall of insects and cause insect death. $N$-Acyl homoserine lactonase (AiiA) is an enzyme that can degrade $N$-acyl homoserine lactones (AHLs) and is a signal molecule of bacteria, which acts as a signaling molecule of the gram-negative bacterial quorum sensing system and participates in the expression regulation of the pathogenic genes ${ }^{39}$. The AiiA gene-expressing protein contributes to the degradation of AHL molecules, it can reduce the concentration of AHLs by hydrolyzing the lactone bond of AHLs that declines the harm caused by pathogens. Previous studies have shown that AiiA has the effect of enhancing the resistance of Zwittermicin to soft rot ${ }^{40}$. Therefore, the AiiA gene of strain HD521 may have a synergistic effect to Rhizoctonia solani AG 1 IB. The chromosome of strain HS18-1 encodes five virulence factors such as Hemolytic Enterotoxin, S-laryer protein, Phospholipase C, Chitinase, and $N$-acyl homoserine lactonase (AiiA). But strain HS18-1 chromosome have not subunit B which is necessary for hemolytic in enterotoxin. It contains subunit L1 and L2. The chromosome of strain HS18-1 encodes 8 hemolytic enterotoxin, 5 S-laryer proteins, 5 phospholipases, 2 chitinases, and $5 \mathrm{~N}$-acyl homoserine lactonases (AiiA). In comparison of HS18-1 with HD521, the strain HS18-1 does not encode Immune Inhibitor A, Zwittermicin A-resistance protein and metalloprotease.

Plasmid analysis. Bt strain HD521 contains 6 plasmids and codes a total of 772 predicted genes, the smallest plasmid is pBTHD521-1with a length of $7042 \mathrm{bp}$ and encodes 11 functional genes, the largest plasmid is pBTHD521-6 with a length of 314,883 bp and encodes 256 functional genes. Some of them, pBTHD521-5 and pBTHD521-6, are used as plasmid which contain the insecticidal crystal protein. However, pBTHD521-1, pBTHD521-2, pBTHD521-3, and pBTHD521-4 are used as plasmid without any insecticidal crystal protein. The 


\begin{tabular}{|c|c|c|c|c|c|}
\hline \multirow[b]{2}{*}{ Virulence factor } & \multicolumn{2}{|l|}{ HD521 } & \multirow[b]{2}{*}{ Virulence factor } & \multicolumn{2}{|l|}{ HS18-1 } \\
\hline & Annotation Number & Gene function & & Annotation Number & Gene function \\
\hline \multirow{3}{*}{ Immune inhibitor } & NF53_1173 & Immune inhibitor A & & & \\
\hline & NF53_2862 & Immune inhibitor $\mathrm{A}$ & & & \\
\hline & NF53_2863 & Immune inhibitor $\mathrm{A}$ & & & \\
\hline \multirow{10}{*}{ Hemolytic enterotoxin } & NF53_1020 & $\begin{array}{l}\text { Trifolitoxin immunity } \\
\text { domain protein }\end{array}$ & Hemolytic enterotoxin & AC241_11040 & Hemolysin D \\
\hline & NF53_1002 & $\begin{array}{l}\text { Gamma-hemolysin } \\
\text { component B }\end{array}$ & & AC241_11455 & Hemolysin BL lytic component L2 \\
\hline & NF53_1695 & Hemolytic enterotoxin & & AC241_17290 & Hemolysin II \\
\hline & NF53_1696 & $\begin{array}{l}\text { Non-hemolytic entero- } \\
\text { toxinlytic component } \\
\text { L1 }\end{array}$ & & AC241_27105 & Hemolysin \\
\hline & NF53_2062 & Hemolysin-3 & & AC241_29375 & Hemolysin BL lytic component L2 \\
\hline & NF53_3001 & $\begin{array}{l}\text { Hemolysin BL-binding } \\
\text { componen }\end{array}$ & & AC241_29380 & Hemolysin BL lytic component L1 \\
\hline & NF53_3002 & $\begin{array}{l}\text { Hemolysin BL-binding } \\
\text { component }\end{array}$ & & AC241_29385 & Hemolysin \\
\hline & NF53_3003 & $\begin{array}{l}\text { Tripartite hemolysin BL } \\
\text { component L1 }\end{array}$ & & AC241_30075 & Hemolysin D \\
\hline & NF53_3004 & $\begin{array}{l}\text { Hemolysin BL lytic } \\
\text { component L2 }\end{array}$ & & & \\
\hline & NF53_3004 & Hemolysin-3 & & & \\
\hline \multirow{5}{*}{ S-laryer protein } & NF53_0786 & S-layer domain protein & S-laryer protein & AC241_02460 & S-layer protein \\
\hline & NF53_0890 & $\begin{array}{l}\text { S-layer Protein/pep- } \\
\text { tidoglycanendo-beta- } \\
N \text {-acetylglucosami- } \\
\text { nidase }\end{array}$ & & AC241_04995 & S-layer protein \\
\hline & \begin{tabular}{|l|} 
NF53_0997 \\
\end{tabular} & S-layer protein & & AC241_05720 & S-layer protein \\
\hline & NF53_1016 & S-layer protein & & AC241_05725 & S-layer protein \\
\hline & NF53_1803 & $\begin{array}{l}\text { S-layer Protein/pep- } \\
\text { tidoglycanendo-beta- } \\
N \text {-acetylglucosami- } \\
\text { nidase }\end{array}$ & & AC241_30720 & S-layer protein \\
\hline \multirow{6}{*}{ Phospholipase C } & NF53_0580 & Phospholipase C & Phospholipase C & AC241_03515 & Phospholipase C \\
\hline & NF53_2241 & Phosphoesterase & & AC241_03520 & Phospholipase C \\
\hline & \begin{tabular}{|l|} 
NF53_2399 \\
\end{tabular} & Patatin phospholipase & & AC241_10060 & Phospholipase \\
\hline & NF53_4723 & Phospholipase YtpA & & AC241_23600 & Phospholipase \\
\hline & \begin{tabular}{|l|} 
NF53_0581 \\
\end{tabular} & Sphingomyelinase $\mathrm{C}$ & & & \\
\hline & & $\begin{array}{l}\text { 1-phosphatidylinositol } \\
\text { phosphodiesterase }\end{array}$ & & AC241_31980 & Phospholipase C \\
\hline \multirow{2}{*}{$\begin{array}{l}\text { Zwittermicin A-resist- } \\
\text { ance protein }\end{array}$} & NF NF53_370153_2753 & $\begin{array}{l}\text { Zwittermicin A-resist- } \\
\text { ance protein }\end{array}$ & & & \\
\hline & NF53_3078 & $\begin{array}{l}\text { Zwittermicin A resist- } \\
\text { ance protein zmaR }\end{array}$ & & & \\
\hline \multirow{3}{*}{ Metalloprotease } & NF53_1014 & Metalloprotease & & & \\
\hline & NF53_1365 & Metalloprotease & & & \\
\hline & NF53_2033 & Neutral metalloprotease & & & \\
\hline \multirow{2}{*}{ Chitinase } & NF53_0359 & Chitinase A1 & Chitinase & AC241_02250 & Chitinase \\
\hline & NF53_3663 & Chitinase D & & AC241_18365 & Chitinase \\
\hline \multirow{5}{*}{ AiiA } & \multirow{5}{*}{ NF_3317 } & \multirow{5}{*}{$\begin{array}{l}\text { N-Acyl homoserine } \\
\text { lactonase, AiiA }\end{array}$} & \multirow{5}{*}{ AiiA } & AC241_03670 & $\mathrm{N}$-Acyl homoserine lactonase, AiiA \\
\hline & & & & AC241_06965 & N-Acyl homoserine lactonase \\
\hline & & & & AC241_16885 & N-Acyl homoserine lactonase \\
\hline & & & & AC241_24135 & $\mathrm{N}$-Acyl homoserine lactonase \\
\hline & & & & AC241_24135 & $\mathrm{N}$-Acyl homoserine lactonase \\
\hline
\end{tabular}

Table 2. Virulence factors of Bacillus thuringiensis strain HD521 and HS18-1.

whole length of plasmid pBTHD521-5 is 253,580 bp and encodes three cry7 genes named as cry7Da1, cry7Ga2 and cry7Fb3 (Fig. 2A), the gene cry7Ga2 located on sense strand while gene cry7Fb3 and cry7Da1 located on antisense strand.

The IS6 family of insertion sequence located on the downstream sequence of gene cry7Fb3 and cry7Da1, and the IS $231 \mathrm{~B}$ family of insertion sequence located on the upstream sequence of gene cry7Ga2. Plasmid pBTHD521-5 also encodes the plasmid replication protein RepX and conjugal transfer protein TraG that means 

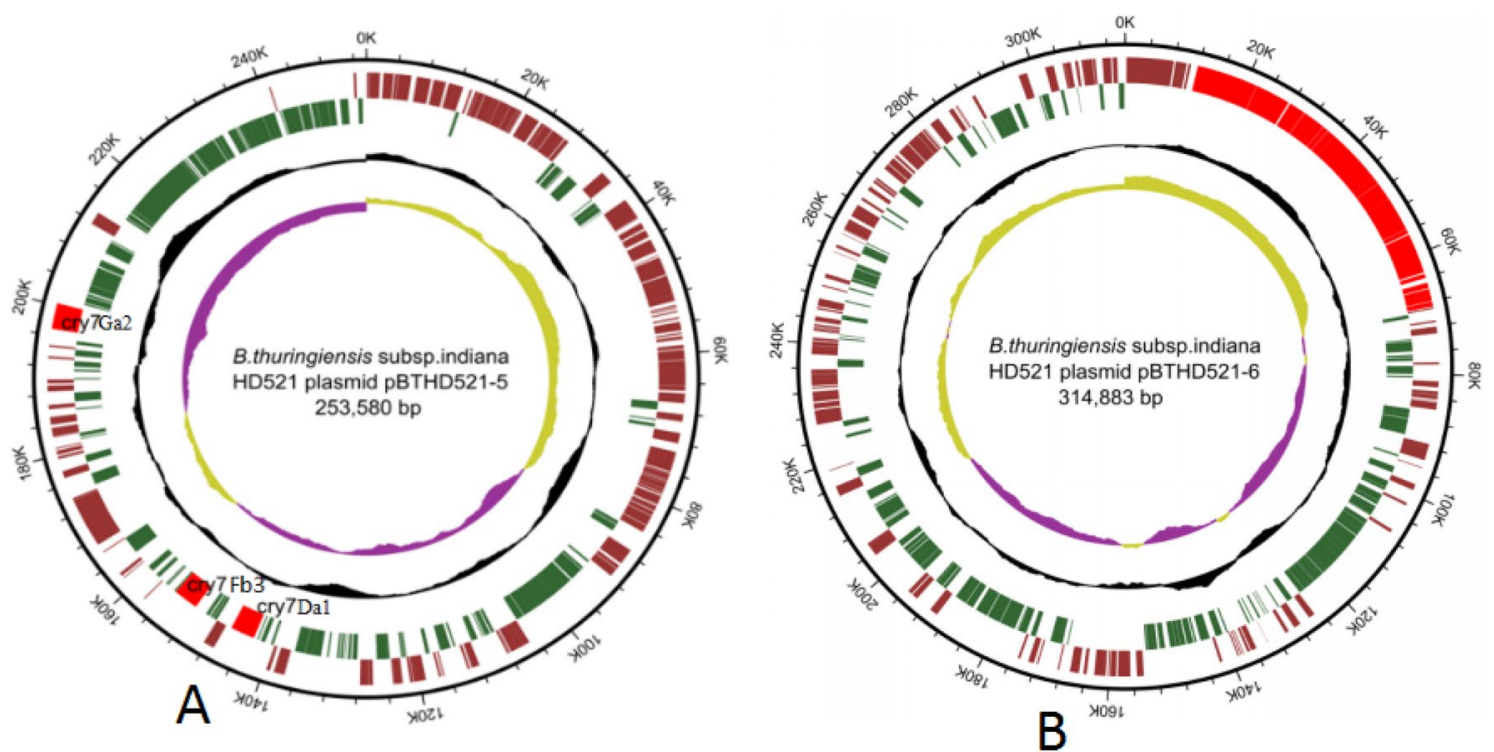

Figure 2. Circular representation of plasmids pBTHD521-5 and pBTHD521-6. (A) Circular representation of plasmid pBTHD521-5 displaying relevant genome features. (B) Circular representation of plasmidpBTHD521-6 displaying relevant genome features.

the replication mode of this plasmid is bidirectional replication and can transfer between different strains. The whole length of plasmid pBTHD521-6 is $314,883 \mathrm{bp}$, encoding the ZwA virulence factor and consisted by 22 ZwA biosynthesis relevant genes that are zmaA, zmaB, zmaC, zmaD, zmaE, zmaR, zmaF, zmaG, zmaH, zmaI, zmaJ, zmak, zmaL, zmaM, zmaN, zmaO, zmaP, zmaQ, zmaS, zmaT, zmaU, and zmaV and its through NRPS and PKS biosynthesis pathway to synthesis (Fig. 2B).

$B t$ strain HS18-1 contains nine plasmids and codes a total of 892 predicted genes, the smallest plasmid is pHS18-9 with a length of 7386 bp that encodes 4 functional genes, and the largest plasmid is pHS18-1 with a length of 509,170 bp that encodes 417 functional genes. Some of them, pHS18-2, pHS18-4 and pHS18-9 are used as plasmids which contain the insecticidal crystal proteins. However, pHS18-1, pHS18-3, pHS18-5, pHS18-6, pHS18-7, and pHS18-8 are the plasmids without any insecticidal crystal protein. Plasmid pHS18-2 encodes eight insecticidal genes e.g.cry30Ea3 + orf2, cry50Aa1 + orf2, cry30Ga1 + orf2, cry71Aa1 + orf2, cry72Aa1 + orf2, cry70Aa1, cry60Ab1, and cry4Cb1 (Fig. 3A). Plasmid pHS18-4 encodes insecticidal gene cry56Aa3 + orf2 (Fig. 3B). Plasmid pHS18-9 encodes insecticidal gene cry54Ba (Fig. 3C).

The insecticidal genes encoded by HS18-1 are like the genes encoded by HD521, beside these genes there are some mobile elements such as IS4 family of insertion sequence located in the downstream sequence of cry30Ga1 + orf2, IS4 sequence located in the in the upstream sequence of cry71Aa1 + orf2, Tn 3 and IS231C located in the upstream and downstream sequences of cry30Ea1 + orf2, respectively. And IS231C in the upstream and downstream sequence of cry30Ea1 + orf2, IS231 sequence located in the downstream sequence of cry4Cb1. It reveals that the cry genes combined with mobile elements as genomic island in the genome.

Insertion sequence analysis. Insertion sequence (IS) is a movable element that causes genomic plasticity and its main feature is the transposition between different sites within the genome. A basic IS element includes a site-specific recombinase (transposase) and flanking repetitive DNA sequences ${ }^{41}$. Different IS sequence elements have great difference in transposition mechanisms and target specific sites, such as IS7 and IS30 $0^{42,43}$. By comparing ISin the genome of both strains, HD521 and HS18-1 (Table 3), we found that the family and number of IS have significant difference in the distribution of the genome. Among them, the number of distribution of strain HS18-1 is the largest, and the IS family is the most abundant.

IS of four families were found in the genome of HD521 by IS sequence analysis. We found that IS family IS6 and IS110 have one copy, respectively. But the insert sequence of IS200_IS605_ssgr_IS1341 family has two copies (Table 3). Bt HD521 contains 6 plasmids and 4 types of IS sequences. Among them, the plasmids pBTHD521-1, pBTHD521-2, pBTHD521-3 and pBTHD521-4 did not contain any IS and these are small plasmids with length of $7 \mathrm{kbp}, 50 \mathrm{kbp}, 71 \mathrm{kbp}$ and $71 \mathrm{kbp}$, respectively. The plasmid-encoded transposase gene analysis revealed that pBTHD521-5 and pBTHD521-6 contain 4 and 3 IS families, respectively. Their IS are mainly focused in the IS200_IS605_ssgr_IS1314, IS6, IS4_ssgr_IS231, and IS200_IS605 families (Table 4). Through the distribution of the IS on the plasmids, we can perceive that the IS of $B t$ is often found in some larger plasmids, so the evolution rate of the endogenous large plasmid of $B t$ is larger than that of the endogenous small plasmid. In the genome and plasmid of HD521, we found that there are 4 IS on the genome and 17 IS on the plasmids. The family of IS shared by the plasmid and genome are IS200_IS605_ssgr_IS1341 and IS6. Besides, the genome also contains two specific families that are IS607 and IS110 and plasmid contains a specific IS231 family along with two subfamilies, IS231B and IS231E. This suggests the indication of the rate of plasmid evolution is faster than the evolution of the genome. 


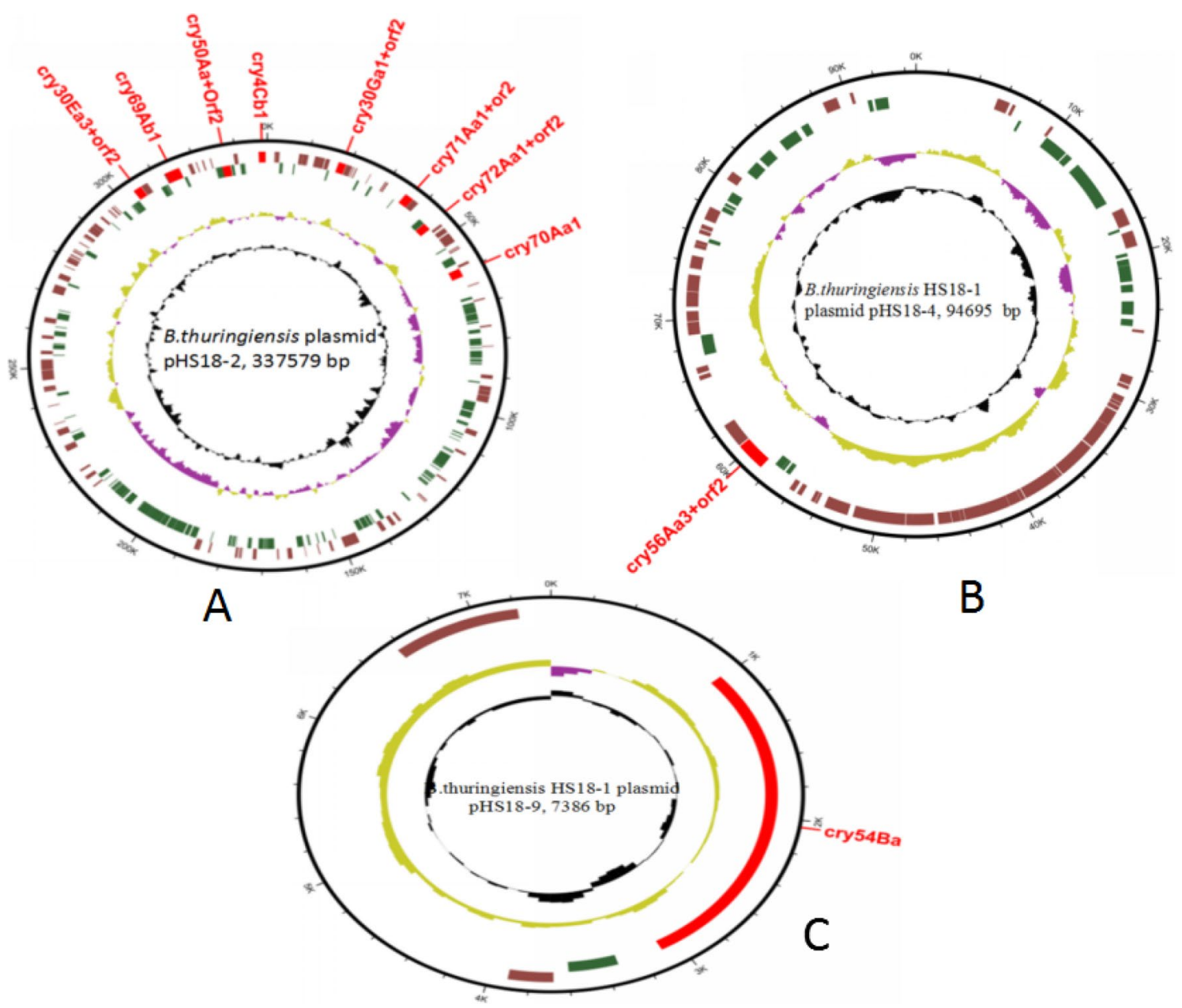

Figure 3. Circular representation of plasmids pHS18-2, pHS18-4 and pHS18-9. (A) Circular representation of plasmid pHS18-2 displaying relevant genome features. (B) Circular representation of plasmid pHS18-4 displaying relevant genome features. (C) Circular representation of plasmid pHS18-9 displaying relevant genome features.

\begin{tabular}{|c|c|c|c|c|c|}
\hline \multirow[b]{2}{*}{ IS sequence family } & \multicolumn{2}{|l|}{ HD521 } & \multirow[b]{2}{*}{ IS sequence family } & \multicolumn{2}{|l|}{ HS18-1 } \\
\hline & Characterization $^{\mathrm{a}}$ & $\begin{array}{l}\text { Start and end } \\
\text { position }\end{array}$ & & Characterization $^{\mathrm{a}}$ & Start and end position \\
\hline \multirow{2}{*}{$\begin{array}{l}\text { IS200_IS605_ssgr_ } \\
\text { IS1341 }\end{array}$} & \multirow{2}{*}{$1 / 0 / 0 / 0$} & \multirow{2}{*}{$3,517,174-3,515,052$} & \multirow{2}{*}{$\begin{array}{l}\text { IS200_IS605_ssgr_ } \\
\text { IS1314 }\end{array}$} & \multirow{2}{*}{$1 / 0 / 0 / 1$} & $1,950,239-1,953,704$ \\
\hline & & & & & $4,239,014-4,235,659$ \\
\hline \multirow{2}{*}{ IS6 } & \multirow{2}{*}{$1 / 0 / 0 / 0$} & \multirow{2}{*}{$3,501,376-3,503,581$} & \multirow{2}{*}{ IS3_ssgr_IS150 } & \multirow{2}{*}{$35 / 1 / 0 / 0$} & $1,908,915-1,912,268$ \\
\hline & & & & & \begin{tabular}{|l|}
$1,024,093-1,020,937$ \\
\end{tabular} \\
\hline IS607 & $1 / 0 / 0 / 0$ & $332,416-335,545$ & IS607 & $2 / 0 / 0 / 0$ & $1,222,989-1,226,127$ \\
\hline \multirow{2}{*}{ IS 110} & \multirow{2}{*}{$1 / 0 / 0 / 0$} & \multirow{2}{*}{ 3196134-3192899 } & \multirow{2}{*}{ IS 110} & \multirow{2}{*}{$0 / 2 / 0 / 0$} & $5,004,244-5,007,064$ \\
\hline & & & & & $5,004,244-5,007,064$ \\
\hline
\end{tabular}

Table 3. The varieties and quantities of IS in HD521 and HS18-1 genome. ${ }^{\mathrm{a} C o m p l e t e}$ sequence/partial sequence/pseudogenes/unknown sequence.

By analysing the HD521 whole-genome annotation results and ISFINDER data, we found a complete IS607 family IS in the HD521 genome. It does not contain an inverted repeat region (IR), but it encodes two ORFs; one encodes a $1131 \mathrm{bp}$ transposase gene, and the other encodes a Haloacid Dehalogenase which plays a crucial role to carry out dehalogenation, phosphoryl transfer and hydrolysis of phosphate salts by forming covalent enzymes.

Meanwhile, we also found a complete IS110 family of IS in the HD521 genome, it also does not contain an IR region with similar to IS family IS200_605, IS607. But the difference is, IS100 family contains a conserved amino-terminal region of pilin gene inverting protein (PIVML). Through analysis we found that IS110 family 


\begin{tabular}{|c|c|c|c|}
\hline Plasmid & IS sequence family & Characterization $^{\mathrm{a}}$ & Start and end position (bp) \\
\hline \multicolumn{4}{|l|}{ pBTHD521-1 } \\
\hline \multicolumn{4}{|l|}{ pBTHD521-2 } \\
\hline \multicolumn{4}{|l|}{ pBTHD521-3 } \\
\hline \multicolumn{4}{|l|}{ pBTHD521-4 } \\
\hline \multirow{10}{*}{ pBTHD521-5 } & \multirow{3}{*}{ IS200_IS605_ssgr_IS1341 } & \multirow{3}{*}{$3 / 0 / 0 / 0$} & 181570_184684 \\
\hline & & & \begin{tabular}{|l|}
$69596 \_72947$ \\
\end{tabular} \\
\hline & & & 191964_189733 \\
\hline & \multirow{4}{*}{ IS6 } & \multirow{4}{*}{$2 / 0 / 0 / 2$} & 143434_140984 \\
\hline & & & 156586_158982 \\
\hline & & & 152421_150180 \\
\hline & & & 201548_199369 \\
\hline & \multirow{2}{*}{ IS4_ssgr_IS231 } & \multirow{2}{*}{$2 / 0 / 0 / 2$} & 145896_149385 \\
\hline & & & 189234_185802 \\
\hline & IS200_IS605 & $2 / 1 / 0 / 0$ & 117482_113986 \\
\hline \multirow{7}{*}{ pBTHD521-6 } & IS200_IS605_ssgr_IS1341 & $2 / 0 / 0 / 0$ & 203973_200852 \\
\hline & \multirow{5}{*}{ IS4_ssgr_IS 231} & \multirow{5}{*}{$5 / 0 / 0 / 0$} & 310195_314508 \\
\hline & & & 238504_235158 \\
\hline & & & 83240_86681 \\
\hline & & & 271106_274295 \\
\hline & & & 267744_269823 \\
\hline & IS200_IS605 & $1 / 0 / 0 / 0$ & 194062_192074 \\
\hline
\end{tabular}

Table 4. The total varieties and quantities of IS sequences in HD521 plasmids. ${ }^{a}$ Complete sequence/partial sequence/pseudogenes/unknown sequence.

includes two ORF sequences, one ORF encodes a 573 bp DNA dissociation enzyme gene and it is a specific DNA recombination site; its $\mathrm{N}$ terminus has a DNA activation site while $\mathrm{C}$-terminal can form a helical loop spiral structure. The other one encodes a 1236 bp DNA transposase gene of DEDD_Tnp_IS110 family specific conserved site, which has a great significance to the efficient transposition of DNA.

The first type of IS, IS200_IS605_ssgr_IS1341 on plasmid pBTHD521-5 has 3 copies, which have an ORFB structure similar to IS family of IS110, the C terminus of ORFB has four typical cysteine residues with an ability to combine with zinc. Therefore, the $\mathrm{C}$ terminus is mainly used as a DNA binding site in transposition process ${ }^{44}$. By comparing the upstream and downstream genes in IS, we found that the first IS1314 was inserted into C1qtnf9 $(\mathrm{C} 1 \mathrm{q}$ and tumor necrosis factor related protein 9) protein of house mouse. However, the 3' end of the IS1314 sequence can form a complete ORF with the downstream C1qtnf9, thus the insertion of IS1314 sequence brings an exogenous gene to the HD521 genome. But, the insertion of the second IS did not result in a change of functional gene and did not carry the insertion of a new heterologous gene.

According to the transposase gene and ISsaga results, we found that plasmid pBTHD521-6 contains 2 copies of the IS IS200_IS605_ssgr_IS1341 family, 1 copy of the IS IS200_IS605 family, and 5 copies of the IS IS4_ ssgr_IS231 family. At the same time, IS4_ssgr_IS231 family also includes subfamily insertion sequences IS231B $(238,504-235,158 \mathrm{bp})$ and IS231E $(267,744-269,823 \mathrm{bp})$, these subfamily insertion sequences generally have a transposase gene which contains ORF containing Integrase binding domain, Helix-turn-helix (HTH) DNA binding site, and DDE structure. The DDE structure has three carboxylic acid residues, and they can combine with metal ions which participate in catalytic DNA cutting to catalytic DNA cleavage, and to transcript regulator. IS231 IS family also contains some enzymes which participate in the metabolism of amino acid and nucleic acid, such as proline dehydrogenase and ribose triphosphate deoxyribonucleoside reductase.

The HS18-1 genome contains 42 copies of the transposase gene and IS family IS3_ssgr_IS150 contains 36 copies, IS200_IS605_ssgr_IS1314, IS607 and IS110 have two copies, respectively (Table 3). However, the transposase gene of IS607 family contains a helix-trans-helical DNA domain at the N terminus and four conserved cysteine residues at the C terminus, and IS110 family has a typical DEDD structure. The IS150 of IS3 family is similar to IS607, also has a helix-trans-helical DNA domain at the $\mathrm{N}$ terminus, but contains an integrase core binding domain at its $\mathrm{C}$ terminus. The pHS18-2 plasmid encodes 62 transposase genes and contains eight IS families (Table 5). IS family IS200_IS605_ssgr_IS1341 contains a zinc finger structure that combines with DNA at the C-terminal of the transposon, its transposase gene has only $82 \%$ homology with other by comparison in NCBI database, which enables to perceive that it might be a new type of IS. IS family IS3_ssgr_IS3 has only $84 \%$ homology with the transposase gene of Bacillus cereus, its DNA binding domain is a helix-turn-helix structure, and it contains a DNA integrase gene, thus it may also be a new class of IS3 family. IS family IS4_ssgr_IS231 has 28 copies, IS6 has 13 copies, IS3_ssgr_IS150 has 14 copies, IS1182 and IS110 have two copies, respectively. The pHS18-4 plasmid encodes five copies of IS family IS4_ssgr_IS231 and contains a cry56Aa3 + orf2 gene, the upstream and downstream sequences of cry56Aa3 + orf2 gene have a IS231 insertion sequence, respectively. The pHS18-1 plasmid contains 15 transposase genes and encodes three IS families, of these three families 


\begin{tabular}{|c|c|c|}
\hline IS sequence family & Characterization $^{\mathrm{a}}$ & Start and end position (bp) \\
\hline \begin{tabular}{|l} 
IS200_IS605_ssgr_IS1341 \\
\end{tabular} & $0 / 0 / 0 / 1$ & $220,443-222,873$ \\
\hline IS3_ssgr_IS3 & $0 / 0 / 0 / 1$ & $20,655-22,962$ \\
\hline \multirow{5}{*}{ IS6 } & \multirow{5}{*}{$8 / 5 / 0 / 0$} & $5003-2134$ \\
\hline & & $133,763-136,448$ \\
\hline & & $40,062-42,927$ \\
\hline & & $330,134-327,448$ \\
\hline & & $7128-4766$ \\
\hline \multirow{5}{*}{ IS3_ssgr_IS150 } & \multirow{5}{*}{$8 / 6 / 0 / 0$} & $242,578-245,931$ \\
\hline & & $744-3899$ \\
\hline & & $21,107-23,747$ \\
\hline & & $318,954-316,586$ \\
\hline & & $318,212-315,994$ \\
\hline \multirow{18}{*}{ IS4_ssgr_IS231 } & \multirow{18}{*}{ 0/27/0/1 } & $312,057-308,732$ \\
\hline & & $1-2663$ \\
\hline & & $276,119-278,678$ \\
\hline & & $285,805-283,497$ \\
\hline & & $103,852-107,341$ \\
\hline & & $275,444-278,090$ \\
\hline & & $25,974-23,447$ \\
\hline & & $33,315-30,848$ \\
\hline & & $257,882-255,442$ \\
\hline & & \begin{tabular}{|l|}
$258,377-256,039$ \\
\end{tabular} \\
\hline & & \begin{tabular}{|l|}
$32,203-29,895$ \\
\end{tabular} \\
\hline & & $61,006-63,314$ \\
\hline & & \begin{tabular}{|l|}
$32,484-30,239$ \\
\end{tabular} \\
\hline & & $255,923-253,768$ \\
\hline & & $336,382-337,578$ \\
\hline & & $258,012-255,875$ \\
\hline & & $307,177-309,307$ \\
\hline & & $32,820-30,716$ \\
\hline Tn3 & $0 / 1 / 0 / 0$ & $179,485-183,205$ \\
\hline \multirow{2}{*}{ IS 1182} & \multirow{2}{*}{$1 / 1 / 0 / 0$} & $39,248-42,104$ \\
\hline & & $38,601-41,172$ \\
\hline IS110 & $2 / 0 / 0 / 0$ & $257,280-254,069$ \\
\hline
\end{tabular}

Table 5. The varieties and quantities of IS sequences in plasmid pHS18-2. ${ }^{\mathrm{a}}$ Complete sequence/partial sequence/pseudogenes/unknown sequence.

IS200_IS605_ssgr_IS1341 have one copy, IS4_ssgr_IS231 have four copies, and IS200_IS605 have 11 copies. The pHS18-3 plasmid encodes five copies of IS family IS6 while pHS18-5, pHS18-6, pHS18-7, pHS18-8, and pHS18-9 have no IS.

Sequence analysis of lysogenic phage of the chromosome. The sequence of HD521 chromosome analysed by PHASTER showed that the HD521 chromosome contains 6 lysogenic phage genome regions (Table 6). Among them, the two sequence regions (sequence 1 and sequence 2 ) are complete with sequence lengths of $66.3 \mathrm{kbp}(2,289,187-2,355,583 \mathrm{bp})$ and $40.6 \mathrm{kbp}(3,817,538-3,858,166 \mathrm{bp})$ encoding 89 and 29 CDS sequences, respectively. The three sequence regions (sequence 3 , sequence 4 , and sequence 5 ) are not complete with lengths of $20.3 \mathrm{kbp}(1,167,554-1,187,932 \mathrm{bp}), 22.3 \mathrm{kbp}(1,994,291-2,016,618 \mathrm{bp})$, and 23.6. $\mathrm{Kbp}(3,817,538-$ $3,858,166 \mathrm{bp}$ ) encoding 23,18 and 24 CDS sequences, respectively. Sequence 6 may belong to lysogenic phage, having length of $13.6 \mathrm{kbp}(2,014,092-2,027,776 \mathrm{bp})$ encodes $18 \mathrm{CDS}$ sequences.

Sequence 1 has homology with the prophage sequence of 13 species, 79 of the 89 CDS sequences participate in the coding of phage functional proteins, and $10 \mathrm{CDS}$ sequences encode hypothetical proteins. Sequence 2 has homology with the prophage sequence of 14 species, 26 of the 29 CDS sequences participate in the coding of phage functional proteins, and 3 CDS sequences participate in the coding of hypothetical proteins. Sequence 3 has homology with the prophage sequence of 13 species, 15 of the 23 CDS sequences participate in the coding of phage functional proteins, and 8 CDS sequences participate in the coding of hypothetical proteins. Sequence 4 has homology with the prophage sequence of 7 species, 13 of the 18 CDS sequences participate in the coding of phage functional proteins, and 5 CDS sequences participate in the coding of hypothetical proteins. Sequence 


\begin{tabular}{|c|c|c|c|c|c|c|}
\hline Sequence number & Length (kbp) & $\begin{array}{l}\text { Number of encoded } \\
\text { CDS }\end{array}$ & $\begin{array}{l}\text { Starting position } \\
\text { (bp) }\end{array}$ & Possible prophage & $\mathrm{G}+\mathrm{C}$ content $(\%)$ & Integrity \\
\hline Sequence 1 & 66.3 & 89 & $2,289,187-2,355,583$ & $\begin{array}{l}\text { PHAGE_Bacill_ } \\
\text { phBC6A51_ } \\
\text { NC_004820 }\end{array}$ & 37.43 & $\mathrm{Y}$ \\
\hline Sequence 2 & 40.6 & 29 & $3,817,538-3,858,166$ & $\begin{array}{l}\text { PHAGE_Geobac_ } \\
\text { GBSV1_NC_008376 }\end{array}$ & 34.59 & $\mathrm{Y}$ \\
\hline Sequence 3 & 20.3 & 23 & $1,167,554-1,187,932$ & \begin{tabular}{|l} 
PHAGE_Entero_ \\
phi92_NC_023693
\end{tabular} & 36.2 & $\mathrm{~N}$ \\
\hline Sequence 4 & 22.3 & 18 & $1,994,291-2,016,618$ & $\begin{array}{l}\text { PHAGE_Bacill_ } \\
\text { phBC6A52_- } \\
\text { NC_004821 }\end{array}$ & 34.82 & $\mathrm{~N}$ \\
\hline Sequence 5 & 23.6 & 24 & $3,817,538-3,858,166$ & $\begin{array}{l}\text { PHAGE_Brevib_ } \\
\text { Jenst_NC_028805 }\end{array}$ & 35.23 & $\mathrm{~N}$ \\
\hline Sequence 6 & 13.6 & 20 & $2,014,092-2,027,776$ & $\begin{array}{l}\text { PHAGE_Rhizob_ } \\
\text { vB_RleS_L338C_ } \\
\text { NC_023502 }\end{array}$ & 36.76 & Q \\
\hline
\end{tabular}

Table 6. The pro-phage sequences in the chromosome DNA of strain HD521. Y: complete; N: incomplete; Q: unknown.

\begin{tabular}{|l|l|l|l|l|l|l|}
\hline Sequence number & Length $(\mathbf{k b p})$ & $\begin{array}{l}\text { Number of encoded } \\
\text { CDS }\end{array}$ & $\begin{array}{l}\text { Starting position } \\
\text { (bp) }\end{array}$ & Possible prophage & G+C content (\%) & Integrity \\
\hline Sequence 1 & 27.1 & 35 & $2,506,943-2,534,097$ & $\begin{array}{l}\text { PHAGE_Bacill_ } \\
\text { phIS3502_ } \\
\text { NC_019502 }\end{array}$ & 35.77 & Y \\
\hline Sequence 2 & 20.6 & 23 & $2,489,098-2,509,752$ & $\begin{array}{l}\text { PHAGE_Bacill_ } \\
\text { phBC6A52_ } \\
\text { NC_004821 }\end{array}$ & 32.54 & N \\
\hline Sequence 3 & 43.2 & 54 & $1,376,234-1,419,448$ & $\begin{array}{l}\text { PHAGE_Strept_ } \\
\text { phiARI0131_ } \\
\text { NC_031941 }\end{array}$ & 34.38 & $\mathrm{Q}$ \\
\hline
\end{tabular}

Table 7. The pro-phage sequences in the chromosome DNA of strain HS18-1. Y: complete; N: incomplete; Q: unknown.

5 has homology with the prophage sequence of 11 species, 17 of the 24 CDS sequences participate in the coding of phage functional proteins, and 7 CDS sequences participate in the coding of hypothetical proteins.

Functional analysis of CDS encoded by prophage sequences that show sequence 1 and sequence 2 contain attachment site Left (attL) and attachment site Right (attR), these sites are specific for the integration of the phage DNA or the excision of the Bt HD521 genome. However, the prophage sequence is located between these two attachment sites. Component genes needed by CDS sequence encodes phage integrate or cut with bacterial genome, such as Endolysin, DNA recombination and exonuclease gene, Site-specific recombinase, Exonuclease, and DNA polymerase I encoded by sequence 1. Sequence 2 encodes an Integrase, Resolvase, Site-specific recombinase, Cytokine tail protein, head-tail adaptor, Capsid protein, and Bacterial proteins, etc. Sequence 3 mainly encodes phage-related proteins, such as Tail fiber protein, Calcineurin phosphoesterase, Glycosyltransferase, Collagen triple helix repeat protein, Bacteria encode proteins, and some incomplete phage proteins. Sequence 4 mainly encodes DNA integration, recombination protein, and phage tail protein. Sequence 5 has relatively few CDS that encode functional proteins of phages and does not even contain recombinant related enzymes or phage structural proteins. Sequence 6 has fewer proteins that participate in encoding phages and have only one phage minor tail protein. Similarly, sequences 3, 4, 5, and 6 encode some bacterial-type proteins.

The sequence of HS18-1 chromosome analysed by PHASTER showed HS18-1 chromosome contains 3 lysogenic phage genome regions (Table 7). Among them, sequence 1 is complete and its sequence length is $27.1 \mathrm{kbp}$ $(2,506,943-2,534,097 \mathrm{bp})$ with GC content of $35.77 \%$, and encodes 37 protein sequences. Sequence 2 is incomplete and its length is $20.6 \mathrm{kbp}(2,489,098-2,509,752 \mathrm{bp})$ with GC content of $32.54 \%$, and encodes 24 protein sequences. The length of sequence 3 is $43.2 \mathrm{kbp}(1,376,234-1,419,448 \mathrm{bp})$, its GC content is $34.38 \%$, and encodes 54 protein sequences. Sequence 1 has homology with the prophage sequence of 38 species and its $54.28 \%$ of the protein sequence can be aligned with PHAGE_Bacill_phIS3502_NC_019502. Sequence 1 encodes 35 ORFs and a phage-specific attachment site attL and attR, of them 25 ORF sequences encode prophage proteins, such as the transcription regulators of phage ArpU family, site-specific integrases, phage capsid proteins, phage tail assembly proteins, etc.

Of them 5 ORF sequences encode phage hypothesis proteins, and there are also 5 ORF sequences encode non-phage hypothesis proteins. Sequence 2 has homology with the prophage sequence of 9 species and its $45.45 \%$ of the protein sequence can be aligned with PHAGE_Bacill_phBC6A52_NC_004821. Sequence 2 encodes 23 ORFs and a phage-specific attachment site attL and attR, of them 9 ORF sequences encode prophage proteins, such as DNA integration/recombination/insertion protein, DEAD/DEAH box helix protein, Helix-turn-helix 
protein, Repressor, Replication protein DnaD, Collagen helix repeat protein, etc. Nine ORFs of them encode phage hypothesis proteins, and there are also 4 ORF sequences encode non-phage hypothesis proteins. Sequence 3 has homology with the prophage sequence of 21 species and its $25.92 \%$ of the protein sequence can be aligned with PHAGE_Strept_phiARI0131_NC_031941. Sequence 3 encodes 54 ORFs and two phage-specific attachment site attL and attR, of them 24 ORF sequences encode prophage proteins e.g. phage integrin, membrane producing protein, capsid backbone protein, replication initiation protein, RecT recombinase protein, etc. 24 ORF of them encode phage hypothesis proteins, and there are also 8 ORF sequences encode non-phage hypothesis proteins.

\section{Discussion}

By analysing the genome of strain HD521 and HS18-1, we found that these two genomes encode rich virulence factors, such as S-layer protein, enterotoxin, phospholipase, chitinase, and AiiA, etc. They have an important significance for the insecticidal activity and environmental adaptability of $B t$ strains.

Immune Inhibitor $A$ is a metalloproteinase secreted by $B t$, it is able to degrade antibacterial peptide produced by insects to escape the host's immune system ${ }^{45,46}$. AiiA can hydrolyze AHLs (Acylated Homoserine Lactones) which is bacterial quorum sensing related signaling molecules, its role is to inhibit a variety of bacteria and enhance $B t^{\prime}$ s competitive advantage in the insect gut ${ }^{47,48}$. Chitinase is a soluble extracellular protein and an insecticidal active substance that can help $B t$ strains to degrade chitin in the peritrophic membrane of insect intestines and make it able to enter in the blood cavity through the perforated intestinal tract to cause insect septicaemia that further enhance the insecticidal protein effect of $B t$ strains ${ }^{38,49}$. Simultaneously, the genome of strain HD521 and HS18-1 also encode abundant plasmids, of which HD521 contains 6 plasmids and HS18-1 contains 9 plasmids. For instance, Plasmid pBTHD521-5 contained in strain HD521, encodes three cry7-like insecticidal crystal protein genes, was cry7Fb3, cry7Ga2 and cry7Da1, respectively.

The plasmid of strain HS18-1 encodes 10 insecticidal crystal protein genes, which are distributed in plasmids pHS18-2, pHS18-4 and pHS18-9, respectively. We revealed that these plasmids carry a large number of transcriptional regulatory factors and genes related to the ABC (ATP-binding cassette) protein transport system. The presence of these genes provides an important theoretical basis for understanding their regulatory mechanisms to positively and negatively regulate companion crystal genes. We also found that the insecticidal genes carried by Bt are almost entirely located on large plasmids, but the whole length of plasmid pHS18-9 is only $7386 \mathrm{bp}$ and encodes a cry54Ba gene in the plasmid of HS18-1.

We found that two genomes have abundant IS including IS200_IS605, IS3, IS4, IS6, IS110 and IS1182, complex transposons Tn3, and junctional transfer system protein, analyzed by horizontal gene transfer of the genomes of HD521 and HS18-1. IS605 belongs to IS200/IS605 family, IS605 is widely distributed in Helicobacter pylori, and its terminal is not an inverted repeat sequence and is a forward repeat. IS605 often forms a complex with IS200. IS200 was originally found in Salmonella typhimurium, and its terminal inverted repeat sequence has transposase terminator and block ORF transcription ${ }^{50}$. Moreover, these IS comprised of upstream and downstream sequences of the insecticidal crystal protein, e.g. insertion sequence of IS3 family was comprising downstream sequences of gene cry30Ga1 + orf2, insertion sequence of IS4 and IS6 family were comprising of upstream and downstream sequences of gene cry71Aa1 + orf2 and IS1182 sequence was comprised of downstream sequence of gene cry72Aa1 + orf2. Insertion sequence and transfer system of transposition unit composed by insecticidal crystal protein connected with plasmid is beneficial to horizontal gene transfer of the insecticidal crystal protein gene between the different plasmids of different strains and the different plasmids of same strain, which ultimately plays an important role in the exchange of genetic material and the evolution of population of $B$. thuringiensis.

The IS families and numbers of HD521 and HS18-1 are significantly different in genome distribution, which may be due to the different living environments and population evolution of the two strains. In order to survive and multiply, some strains have enhanced their adaptability to the environment through millions of years of evolution. The insertion sequence has formed a dynamic balance in the adverse and beneficial effects of the host bacteria. The transposition of the insertion sequence mediates genome rearrangement, activates or silences the expression of functional genes, etc., which may cause fatal harm to the host bacteria, and may also enable the host bacteria to acquire new functions, to better adapt to the external environment ${ }^{51}$. For example, there are huge differences in the number of IS4 family insertion sequences in different genomes, which may be mainly related to the living environment and the needs of evolution, but these phenomena show that the insertion sequence plays a very important role in the flexibility and evolution of the genome, rather than a simple "selfish gene" 52 .

Simultaneously, different in the distribution of genome also bring a difference in their functions. Strain HD521 has the characteristics of inhibiting the growth of its hyphae against rice disease-causing bacterium sheath blight AG1 IB (Rhizoctonia solani AG1 IB). Simultaneously, the colony of HD521 can produce brown-red pigment, which causes the colony of AG1 IB to appear brown-red, this may be due to the antagonism of multiple microorganisms. It have been reported that Bacillus thuringiensis can inhibit a variety of plant diseases caused by filamentous fungi and other plant pathogens. When multiple microorganisms grow together, one kind of microorganism produces one or several specific secondary metabolites in assimilation, which changes its microenvironment, thereby inhibiting or even killing another microorganism ${ }^{53}$.

Strain HS18-1 has high toxicity to lepidopteran and dipteran pests. We analyzed the insertion sequence of the plasmid and found that plasmids containing insecticidal crystal protein genes often contains abundant insertion sequence, and these inserted sequences often form a transposable unit with the insecticidal crystal protein gene. This indicates that the evolution and transfer method of insecticidal crystal protein genes on plasmids of different strains or different plasmids of the same strain is mediated by the insertion sequence.

Plasmid analysis showed that: pHS18-2 is a plasmid, which contains the most insecticidal crystal protein genes, and they are cry30Ga1 + orf2, cry71Aa1 + orf2, cry72Aa1 + orf2, cry70Aa1, cry30Ea1 + orf2, cry69Ab1, cry50Aa1 + orf2, and cry4Cb1. Among them, there is a IS4 family insertion sequence located in the upstream 
sequence of cry71Aa1 + orf2, IS6 in the downstream and upstream sequence of cry71Aa1 + orf2, cry72Aa1 + orf2, respectively. IS1182 in the downstream sequence of cry72Aa1 + orf2. We analyzed the gene expression of cry71Aal and cry72Aal and found that these two genes can produce diamond-shaped insecticidal crystal proteins. Insecticidal biological activity testing showed that their crystal protein has good insecticidal activity against the larvae of lepidopteran pests, cotton bollworm, beet armyworm, and diamondback armyworm. The insecticidal crystal protein produced by Bacillus thuringiensis is encoded by genes of different sizes, the largemolecular-weight cry proteins are generally encoded by genes above $2 \mathrm{kbp}$. In this study, cry71Aa1 and cry72Aa1 belong to this type of insecticidal crystal genes. These large-molecular-weight cry genes can produce protein molecules that form independent crystal structures through expression, for example, cryIVD genes can produce irregular hexagonal crystals, and cry8 genes can produce spherical crystals ${ }^{54,55}$.

To date, thousands of $B t$ strains have been identified and isolated but only 24 strains of them found to be fully sequenced The availability and scrutiny of complete genome sequence of strain HD521 and HS18-1 will lay a foundation in $B t$ genome database for further analysis of the generation and regulatory mechanism of cry genes. In summary, the whole genome sequencing and its comparative analysis of both strains (HD521 and HS18-1) will lay out comprehensive perceptions for the genomic diversity and can also be utilized as genomic data support for further strain improvement.

Received: 4 December 2020; Accepted: 22 July 2021

Published online: 16 August 2021

\section{References}

1. Schnepf, E. et al. Bacillus thuringiensis and its pesticidal crystal proteins. Microbiol. Mol. Biol. Rev. 62, 775-806 (1998).

2. Bechtel, D. B. \& Bulla, L. A. Electron microscope study of sporulation and parasporal Crystal formation in Bacillus thuringiensis. J. Bacteriol. 127, 1472-1481 (1976).

3. Ibrahim, M. A., Griko, N., Junker, M. \& Bulla, L. A. Bacillus thuringiensis: A genomics and proteomics perspective. Bioeng. Bugs 1, 31-50 (2010).

4. Feitelson, J. The Bacillus thuringiensis family tree. In Advanced Engineered Pesticides (ed. Kim, L.) 63-71 (CRC Press, 1993).

5. Höfte, H. \& Whiteley, H. R. Insecticidal crystal proteins of Bacillus thuringiensis. Microbiol. Rev. 53, $242-255$ (1989).

6. Krishnan, K., Ker, J. E., Mohammed, S. M. \& Nadarajah, V. D. Identification of glyceraldehyde-3-phosphate dehydrogenase $(\mathrm{GAPDH})$ as a binding protein for a $68-\mathrm{kDa}$ Bacillus thuringiensis parasporal protein cytotoxic against leukaemic cells. J. Biomed. Sci. 17, 86 (2010).

7. Shao, T. M. et al. A Nonribosomal Peptide synthetase gene tzw 1 is involved in Zwittermicin A biosynthesis in Bacillus thuringiensis G03. Curr. Microbiol. 57, 61-65 (2008).

8. Broderick, N. A., Goodman, R. M., Raffa, K. F. \& Handelsman, J. Synergy between zwittermicin A and Bacillus thuringiensis subsp. kurstakiagainst gypsy moth (Lepidoptera: Lymantriidae). Environ. Entomol. 29, 101-107 (2000).

9. Silo-Suh, L. A., Stabb, E. V., Raffel, S. J. \& Handelsman, J. Target range of zwittermicin A, an aminopolyol antibiotic from Bacillus cereus. Curr. Microbiol. 37, 6-11 (1998).

10. Kevany, B. M., Rasko, D. A. \& Thomas, M. G. Characterization of the complete Zwittermicin A biosynthesis gene cluster from Bacillus cereus. Appl. Environ. Microbiol. 75, 1144-1155 (2009).

11. Fang, S. et al. Bacillus thuringiensis bel protein enhances the toxicity of Cry1Ac protein to Helicoverpa armigera larvae by degrading insect intestinal mucin. Appl. Environ. Microbiol. 75, 5237-5243 (2009).

12. Peng, D. et al. A novel metalloproteinase virulence factor is involved in Bacillus thuringiensis pathogenesis in nematodes and insects. Environ. Microbiol. 18, 846-862 (2016).

13. Zwick, M. E. et al. Genomic characterization of the Bacillus cereus sensu lato species: Backdrop to the evolution of Bacillus anthracis. Genome Res. 22, 1512-1524 (2012).

14. Read, T. D. et al. Comparative genome sequencing for discovery of novel polymorphisms in Bacillus anthracis. Science 296, 2028-2033 (2000).

15. Ivanova, N. et al. Genome sequence of Bacillus cereus and comparative analysis with Bacillus anthracis. Nature 423, 87-91 (2003).

16. Read, T. D. et al. The genome sequence of Bacillus anthracis Ames and comparison to closely related bacteria. Nature 423, 81-86 (2003).

17. National Center for Biotechnology Information of Bacillus thuringiensis Genome Database. http://www.ncbi.nlm.nih.gov/genome/ genomes/486.

18. Zerbino, D. R. Using the Velvet de novo assembler for short-read sequencing technologies. Curr. Protoc. Bioinform. 20, 10 (2010).

19. Li, H. \& Durbin, R. Fast and accurate long-read alignment with Burrows-Wheeler transform. Bioinform. Epub. 26, 589-595 (2010).

20. Zerbin, D. R. \& Birney, E. Velvet: Algorithms for de novo short read assemly using de Bruiin graphs. Genome Res. 18, 821-829 (2008).

21. Chin, C. S. et al. Nonhybrid, finished microbial genome assemblies from long-read SMRT sequencing data. Nat. Methods 10, 563-569 (2013).

22. Besemer, J., Lomsadze, A. \& Borodovsky, M. GeneMarks: A self-traning method for prediction of gene starts in microbial genomes. Implications for finding sequence motifs in regulatory regions. Nucleic Acids Res. 29, 2607-2618 (2001).

23. Delcher, A. L., Harmon, D. H., Kasif, S., White, D. \& Salzberg, S. L. Imroved microbial gene identification with GLIMMER. Nucleic. Acids Res. 27, 4636-4641 (1999).

24. Lagesen, K. et al. RNAmmer: Consistent and rapid annotation of ribosomal RNA genes. Nucleic Acids Res. 35, 3100-3108 (2007).

25. Lowe, T. M. \& Eddy, S. R. tRNAscanSE: A program for improved detection of transfer RNA genes in genomic sequence. Nucleic Acids Res. 25, 955-964 (1997).

26. Griffiths-Jones, S. et al. Rfam: Annotating non-coding RNAs in complete genomes. Nucleic Acids Res. 33, D121-124 (2005).

27. Bendtsen, J. D., Nielsen, H., Von Heijne, G. \& Brunak, S. Improved prediction of signal peptides: Signal 3.0. J. Mol. Biol. 340, 783-795 (2004).

28. Krogh, A., Larsson, B., Von Heijne, G. \& Sonnhammer, E. L. Predicting transmenbrane protein topology with a hidden markov model: Application to complete genomes. J. Mol. Biol. 305, 567-807 (2001).

29. Arndt, D. et al. PHASTER: A better, faster version of the PHAST phage search tool. Nucleic Acids Res. 44, W16-W21 (2016).

30. Zhou, Y., Liang, Y., Lynch, K. H., Dennis, J. J. \& Wishart, D. S. PHAST: A fast phage search tool. Nucleic Acids Res. 39, W347-W352 (2011).

31. Delucca, A. J. II., Simonson, J. G. \& Larson, A. D. Bacillus thuringiensis distribution in soil of the United States. Can. J. Microbiol. 27, 865-870 (1981).

32. Li, Q. et al. Complete genome sequence of Bacillus thuringiensis strain HD521. Stand Genom. Sci. 10, 1-8 (2015). 
33. Zhu, J. et al. Characterization of insecticidal crystal protein cry gene of Bacillus thuringiensis from soil of Sichuan Basin, China and cloning of novel haplotypes cry gene. Ann. Microbiol. 59, 1-8 (2009).

34. Li, Q. et al. Complete genome sequence of Bacillus thuringiensis HS18-1. J. Biotechnol. 214, 61-62 (2015)

35. Rahman, S. M. et al. Promotion of cytotoxic T-cell generation in mixed leukocyte culture by phosphatidylinositol-specific phospholipase C from Bacillus thuringiensis. Infect Immun. 63, 259-263 (1995).

36. Driss, F., Kallassy-Awad, M., Zouari, N. \& Jaoua, S. Molecular characterization of a novel chitinase from Bacillus thuringiensis subsp. Kurstaki. J. Appl. Microbiol. 99, 945-953 (2005).

37. Liu, M. et al. Chitinolytic activities in Bacillus thuringiensis and their synergistic effects on Iarvicidal activity. J. Appl. Microbiol. 93, 374-379 (2002).

38. Thamthiankul, S., Moar, W. J., Miller, M. E. \& Panbangred, W. Improving the insecticidal activity of Bacillus thuringiensis subsp. aizawai against Spodoptera exigua by chromosomal expression of a chitinasegene. Appl. Microbiol. Biotechnol. 65, 183-192 (2004).

39. Nierman, W. C. et al. Structural flexibility in the Burkholderia mallei genome. Proc. Natl. Acad. Sci. USA 101, 14246-14251 (2004).

40. Zeng, H. Enhancing Effect of AHL Lactonase on ZwA's Suppression Against Soft Rot Disease in Bacillus cereus (Huazhong Agricultural University, 2006).

41. Chandler, M. \& Mahillon, J. Insertion sequence revisites. Mob. DNA II, 305-366 (2002).

42. Olasz, F. et al. Target specificity of insertion element IS30. Mol. Microbiol. 28, 691-704 (1998).

43. Tettelin, S., Suan-Ngay, S., Tantimavanich, S. \& Panbangred, W. Chitinase from Bacillus thuringiensis subsp. Pakistani. Appl. Microbiol. Biotechnol. 56, 395-401 (2001).

44. Marchler, B. A. et al. CDD: NCBI's conserved domain database. Nucleic Acids Res. 43, D222-226 (2015).

45. Fedhila, S., Nel, P. \& Lereclus, D. The InhA2 metalloprotease of Bacillus thuringiensis strain 407 is required for pathogenicity in insects infected via the oral route. J. Bacteriol. 184, 3296 (2002).

46. Dalhammar, G. Characterization of inhibitor A, a protease from Bacillus thuringiensis which degrades attacins and cecropins, two classes of antibacterial proteins in insects. FEBS J. 139, 247-252 (1984).

47. Zhang, L., Murphy, P. J., Kerr, A. \& Tate, M. E. Agrobacterium conjugation and gene regulation by N-acyl-L-homoserine lactones. Nature 362, 446-448 (1993).

48. Molina, L., Rezzonico, F., Défago, G. \& Duffy, B. Autoinduction in Erwinia amylovora: Evidence of an acyl-homoserine lactone signal in the fire blight pathogen. J. Bacteriol. 187, 3206 (2005).

49. Ding, X. et al. Improving the insecticidal activity by expression of a recombinant crylAc gene with chitinase-encoding gene in Acrystalliferous Bacillus thuringiensis. Curr. Microbiol. 56, 442-446 (2008).

50. Leonard, C., Chen, Y. \& Mahillon, J. Diversity and differential distribution of IS231, IS232 and IS240 among Bacillus cereus, Bacillus thuringiensis and Bacillus mycoides. Microbiology 143, 2537-2547 (1997).

51. Haig, H. \& Kazazian, J. R. Mobile elements: Drivers of genome evolution. Science 303, 1626-1632 (2004).

52. De Palmenaer, D., Siguier, P. \& Mahillon, J. IS4 family goes genomic. BMC Evol. Biol. 8, 18 (2008).

53. Huang, X., Xu, L. L., Huang, R. S. \& Huang, S. S. Research advance in controlling plant diseases by Bacillus subtilis. Biotechnol. Bull. 18, 23-29 (2010).

54. Song, D. \& Shen, Z. Cloning and expression of CryIVD gene of insecticidal crystal protein of Bacillus thuringiensis in the acrystalliferous strain. Insect Sci. 3, 239-246 (1995).

55. Zang, D. K., Zheng, G. L., Zhou, H. X., Li, G. X. \& Li, C. Y. Cloning of cry8Fa2 gene and its expression in Bacillus thuringiensis acrystalliferous mutant strain. ACTA Agric. Boreali Sin. 26, 16-20 (2011).

\section{Acknowledgements}

This study was supported by the Chinese Major Project to Create New Crop Varieties Using Gene Transfer Technology (NO.2011ZX08009-003-001-009) and the Breeding of new varieties of insect-resistant transgenic rice (2016ZX08001-001) for transgenic research.

\section{Author contributions}

H.S. conducted the experiments. X.X. analyzed the results. Q.L., H.L., X.W. and J.S. gave review of the manuscript. L.L. and A.Z. provided development or design of methodology. All authors have read and agreed to the published version.

\section{Competing interests}

The authors declare no competing interests.

\section{Additional information}

Correspondence and requests for materials should be addressed to L.L. or A.Z.

Reprints and permissions information is available at www.nature.com/reprints.

Publisher's note Springer Nature remains neutral with regard to jurisdictional claims in published maps and institutional affiliations.

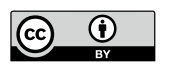

Open Access This article is licensed under a Creative Commons Attribution 4.0 International License, which permits use, sharing, adaptation, distribution and reproduction in any medium or format, as long as you give appropriate credit to the original author(s) and the source, provide a link to the Creative Commons licence, and indicate if changes were made. The images or other third party material in this article are included in the article's Creative Commons licence, unless indicated otherwise in a credit line to the material. If material is not included in the article's Creative Commons licence and your intended use is not permitted by statutory regulation or exceeds the permitted use, you will need to obtain permission directly from the copyright holder. To view a copy of this licence, visit http://creativecommons.org/licenses/by/4.0/.

(C) The Author(s) 2021 